\title{
BENEFITS AND LIMITATIONS TOWARD A SUSTAINABLE ROAD ENVIRONMENT DURING THE YEARS OF ECONOMIC RECESSION
}

\author{
K. VOGIATZIS \& P. KOPELIAS \\ Civil Engineering Department, University of Thessaly, Greece.
}

\begin{abstract}
The prolonged economic crisis in Greece in the last 5 years resulted in a dramatic road traffic volume reduction and as a consequence in environmental road traffic noise diminution. This article analyses this issue with comparisons of measurements of noise, traffic volume and speed, at certain points along the capital's ring motorway, for a 9-year period. Data and comparisons concern measurements taken at 42 locations in Athens ring road during the last 9 years. According to the results, since 2009 - the year with the highest ring road traffic volume - there is a downward trend in both road traffic and environmental noise measurements recorded every year. It is also interesting to point out that until 2009 , at locations where there is high traffic volume and many hours of congestion during the day, there is some minor reduction or even an increase in noise level due to the increase of the average speed. On the other hand, night measurements show that, for economy reasons, driver's speed has dropped to lower levels and thus lower noise level measurements are recorded.

Keywords: economic crisis, sustainability, traffic noise, traffic volume.
\end{abstract}

\section{INTRODUCTION}

The relationship between urban development and its environmental impacts has been covered by many studies in the literature. Button [1] describes the effects in many activities and in environment as well during the periods of economic and urban growth (Fig. 1). Air pollution, traffic noise and congestions are increased in periods of economy growth. Lia et al. [2] propose a numerous indicators and developed a full permutation polygon synthetic indicator method to evaluate the capacity for urban sustainable development at different times. Among others, they suggest the indicator of 'proportion of total hours per year in which noise levels are below the level specified in the national standard'.

The effect, also, for a 'linear' road system such as motorways are studied by Shu et al. [3] who suggest that higher traffic volume leads to a substantial increase in UFPs and (a smaller) increase in noise levels. In such a system, noise barriers are a common protection measure and Ninga et al. [4] investigated two highly trafficked freeways (I-710 and I-5) in Southern California, with two sampling sites for each freeway, one with and the other without roadside noise barriers. The results show the particle number and pollutants concentrations decay exponentially near freeways without the roadside noise barriers.

Traffic volume and relative environmental noise had not always a straight and clear correlation. Fiedler and Zannin [5] indicated that a 50\% reduction in the total vehicle flow, or a 50\% reduction in heavy vehicle flow, would provide a reduction of about $3 \mathrm{~dB}(\mathrm{~A})$ in noise levels while a detailed analysis by Leea et al. [6] about the association between traffic and ambient noise levels in three major cities in the United States showed that urban noise is highly correlated with simultaneously measured traffic but also varied depending on the estimates of traffic use to calibrate noise models. It is likely that noise levels are influenced by other factors such as street width, height and surface material of buildings, the presence of sound wall, green space, slope of roadway, tire-pavement interaction and weather conditions. Also, Gallo et al. [7] provide the first result of an Urban Traffic 


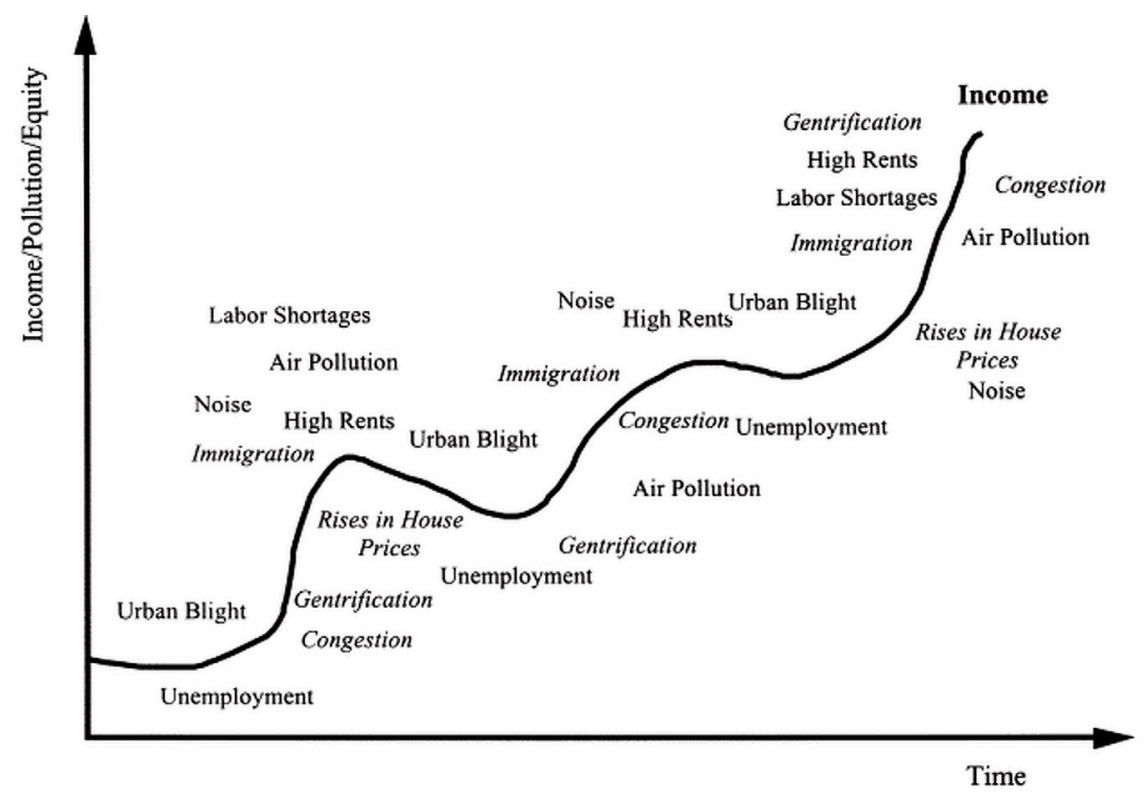

Figure 1: Economic, environmental and urban development factors [1].

Plan (UTP) framework in an Italian city and they conclude that the impact in noise of UTP needs comprehensive indicators to be defined.

While traffic characteristics are critical factors for noise levels, some other studies focused on the calculation and estimation of their effects. A study by Romeu et al. [8] quantifies the error committed when the day time noise level in one street is estimated from a short time measurement covering the issue of the reliability of an assessment in case of absence of continuous measurements of traffic noise. Also, Makarewicz and Galuszka [9] calculated the annual average sound level of the road traffic noise, when the characteristics of the speed-flow diagram are available: the average speed of freely cruising vehicles, capacity of the traffic flow, traffic speed at the traffic flow capacity and the slope of the decreasing traffic speed versus traffic flow. Under any conditions, traffic congestion reduces the annual average sound level. The final conclusion is that strong traffic congestion cannot be ignored in noise prediction and they suggest an additional factor of $\Delta L$ cong on the equation of the annual average sound level, which depends on parameters of the speed-flow diagram.

This article analyses a 9-year period data of traffic volume, speed and noise in Athens ring road, a motorway $70 \mathrm{~km}$ long. During this period, a dramatic economy downturn is observed so the impact of this change in traffic noise and, in general, environmental conditions will be assessed. Attica Toll way in the Athens Ring Road also called 'Attiki Odos' is a pioneering project constructed on a concession basis and constitutes one of the biggest co-financed road projects in Europe. It belongs to the first generation of co-financed projects awarded in Greece during the 1990s and essentially paved the way and laid the foundations for the execution of future successful concession contracts in Greece and other European countries. It extends along $70 \mathrm{~km}$ and constitutes the ring road of the greater metropolitan area of Athens, with some 4.5 million inhabitants. A Full Environmental Noise and Atmospheric Pollution Monitoring program based on (a) eight 
fixed stations and (b) a mobile 24-h monitoring grid for environmental noise monitoring according to the European Directive 2002/49/EC is already fully operational [10]. The motorway operator, to ensure a sustainable operation, has implemented an extended Noise Action Plan (NAP) based on an important anti-noise mitigation measures implementation and monitoring program, as part of the relevant Noise Action Plan (NAP 2010) $[10,11]$ and also operates a Traffic Incident Management scheme to eliminate traffic and environmental impacts of congestions [12]; additional reductions of noise level or air pollution are solely derived by traffic and speed changes during the years.

For a before-after economic crisis comparison, we use traffic noise measurements. Traffic noise is a critical indicator for quality of life, and noise pollution is a growing concern in Europe. Of particular importance is noise from transport and industrial sources, which are addressed by Directive 2002/49/EC relating to the assessment and management of environmental noise, otherwise known as the Environmental Noise Directive (END) [13]. Furthermore, Environmental Noise annoyance especially from airports' operation - is widely accepted as an end-point of environmental noise that can be taken as a basis for evaluating the impact of noise on the exposed population. People annoyed by airport noise may experience a variety of negative responses, such as anger, disappointment, dissatisfaction, withdrawal, helplessness, depression, anxiety, distraction, agitation or exhaustion [14]. For environmental traffic noise mapping, the national French method 'NMPB-Routes-96 (SETRACERTU-LCPCCSTB)' was taken into consideration, as it is presented in the 'Article du 5 mai 1995 relatif au bruit des infrastructures routières, Journal officiel du 10 mai 1995' (French standard 'XPS 31-133') and is incorporated within the Greek legal framework In Greece; Environmental Noise mainly from transportation is regulated by the Ministerial Decision 210474/2012 regarding the 'Determination of the Indicators for the Evaluation of Environmental Noise and the max' allowed Limits of the relevant $\mathrm{L}_{\text {den }}$ and $\mathrm{L}_{\text {night }}$ noise indicators from the operation of transport networks according to the relevant JMD 13586/724 aiming at the harmonization with 2002/49/EC Directive $[13,15,16]$. The scope of this Directive shall apply to environmental noise to which humans are exposed particularly in built-up areas, in public parks, or other quiet area, near schools, hospitals, and other noise sensitive buildings or places and in quiet areas in open country. Member States shall apply the noise indicators Lden and Lnight that shall be determined by means of the assessment methods [17]. The definition of the Lden level (day-evening-night) is defined by the following formula:

$$
L_{d e n}=10 \lg \frac{1}{24}\left(12 * 10^{\frac{L_{d a y}}{10}}+4 * 10^{\frac{L_{\text {evening }}+5}{10}}+8 * 10^{\frac{L_{\text {night }}+10}{10}}\right)
$$

where $\mathrm{L}_{\text {day }}$ is the A-weighted long-term average sound level as defined in ISO 1996-2: 1987 (e.g. ISO [18]), determined over all-the-day periods of a year, $\mathrm{L}_{\text {evening }}$ is the A-weighted long-term average sound level as defined in ISO 1996-2: 1987, determined over all-the-evening periods of a year, $\mathrm{L}_{\text {night }}$ is the A-weighted long-term average sound level as defined in ISO 1996-2: 1987, determined over all-the-night periods of a year.

The new maximum values for the relevant European noise indices introduced by the Ministry of the Environment for Strategic Noise Mapping purposes [15] measured at a height of 3.8-4.0 m and within a minimum distance of $2 \mathrm{~m}$ from the closest - to the road noise source - façade are as follows:

- Environmental Noise Index $\mathrm{L}_{\text {den }} \leq 70 \mathrm{~dB}(\mathrm{~A})$ and

- Environmental Noise Index $\mathrm{L}_{\text {night }} \leq 60 \mathrm{~dB}(\mathrm{~A})$. 


\section{DATA COLLECTION}

Forty-two locations (locations) of 24-h environmental noise measurement along the Athens ring road were selected for the following analysis. These positions were selected because they were monitored continuously during the period from 2005 until 2013 and, therefore, the existing data are fully comparable data over the years. In general, there are two different periods to compare: the period 'before' and the period 'after' 2010, which was the first year of crisis and all relevant economic and traffic indicators turned to negative trend. The locations are both at urban/residential areas with high traffic and semi-urban area.

For each position, the following data were selected:

a. Traffic volume at the noise measuring point: Detailed measurements of traffic (intervals of $20 \mathrm{~s}$ ) were aggregated in hourly traffic volumes that are consistent with noise measurement (hourly basis).

b. The average speed of the section at the measuring point: Speed is measured on hourly basis of the specific day of noise measurement. Then, the 24-h (for $\mathrm{L}_{\text {den }}$ ) and 8-h (for $\mathrm{L}_{\text {night }}$ ) average speed was calculated.

c. The hourly level of noise that is expressed with the $\mathrm{L}_{\mathrm{den}}$ and $\mathrm{L}_{\text {night }}$ indicators.

For further analysis, the following assumptions are considered. First, the traffic volume is considered as 'the number of vehicles that pass through the section of the motorway at the location of noise measurement during the day ( $24 \mathrm{~h}$ ) of the specific day of measurement'. While the noise measurements are implemented in weekdays and usually during spring or early summer, avoiding high or low traffic periods (like summer days, rainy or hot days and holidays), it can be assumed that comparisons of volumes, speeds and noise level between different days of different years are reliable as these days can be considered as typical weekdays.

Also, volumes refer to the total volume (daily, hourly) of the two directions of the motorway at the location of noise measurement. That means that the values represent the flow of six lanes (three per direction) in most of the cases, or four lanes (two per directions) in some others. Finally, according to the traffic data we analyze, the heavy vehicles' percentage is remarkably stable during years and between different parts of the motorway. This ratio is close to $5 \%( \pm 0.5 \%)$ for all cases that are analyzed so the contribution in the noise level is almost the same.

\section{EVOLUTION OF TRAFFIC VOLUMES}

In Greece, from 2010 a dramatic recession of the economy was occurred. In 2013, GDP was declined by $19.4 \%$ compared to 2010 and the unemployment rate increased from $11.9 \%$ in the first quarter of 2010 to $27.6 \%$ in the first quarter of 2013 [19]. Also, during these years, the price of fuels rose significantly. The price of unleaded gasoline was around $1 € / \mathrm{lt}$ at the end of 2009 , reached $1.5 € / 1 \mathrm{t}$ at spring of 2010 and reached in some periods the price of $2 € /$ lt by the beginning of 2012 .

As a result, a significant road traffic volume reduction was recorded. According to the Traffic Management Centre of Athens Metropolitan Area, the drop in traffic on main roads of the capital city was on average from $5 \%$ to $15 \%$, and with reference to the year 2009 , the decrease in many cases reached the percentage of 50\% [20]. In the peripheral motorway of the city of Athens (Attiki Odos Tollway), the number of entries was continually increased until the year 2009 when the greatest number of average daily entries was recorded. This number reached 307.300 vehicles per day on average. Very soon, the number of entries fell back at the level of 2005. Specifically, in 2010 the average number of entries per day was 281.324 and 250.491 in 2011 . The reduction was $8.5 \%$ in 
Table 1: Traffic Evolution of Ring Road of Athens (Attiki Odos), 2005-2013.

\begin{tabular}{lccccccccc}
\hline Year & $\mathbf{2 0 0 5}$ & $\mathbf{2 0 0 6}$ & $\mathbf{2 0 0 7}$ & $\mathbf{2 0 0 8}$ & $\mathbf{2 0 0 9}$ & $\mathbf{2 0 1 0}$ & $\mathbf{2 0 1 1}$ & $\mathbf{2 0 1 2}$ & $\mathbf{2 0 1 3}$ \\
\hline Avg. Daily & 248784 & 270002 & 295140 & 300993 & 307300 & 281324 & 250491 & 215644 & 200473 \\
Entries in the & & & & & & & & & \\
Tollway & & & & & & & & \\
Change & - & $8.50 \%$ & $9.30 \%$ & $2.00 \%$ & $2.10 \%$ & $-8.50 \%$ & $-11.00 \%$ & $-13.90 \%$ & $-7.00 \%$ \\
\hline
\end{tabular}

2010 compared to $2009,11 \%$ in 2011 compared with 2010, $13.9 \%$ in 2012 compared to 2011 and $7 \%$ in 2013 compared to 2012 (Table 1) [12,21].

Finally, according to Hellenic Statistical Authority (ELSTAT), the Household Budget Survey show similar changes in goods and services, which are directly related to traffic volumes. Expenditure for 'Transportation' dropped by $29.6 \%$ in 4 years, and also 'Recreation /culture' and 'Hotels, cafes and restaurants', which mean activities that produce vehicle trips also have a reduction of $34.0 \%$ and $37.4 \%$, respectively [19].

\section{EVOLUTION OF TRAFFIC NOISE}

\subsection{Noise indicators}

Overall, at the 42 locations there is an incremental change of noise indicators until 2008 and 2009, when the indicators begin to fall. The maximum value is $71.3 \mathrm{~dB}(\mathrm{~A})$ for $\mathrm{L}_{\mathrm{den}}$ in 2009 and $63.6 \mathrm{~dB}(\mathrm{~A})$ for $\mathrm{L}_{\text {night }}$ in 2008. The lowest values were recorded in $2013,68.6 \mathrm{~dB}(\mathrm{~A})$ for $\mathrm{L}_{\text {den }}$ and 60.5 for $\mathrm{L}_{\text {night }}$. The relative change between maximum and minimum values (or between the 'before' maximum value and the minimum after the significant decline of traffic volume) is approximately 2.5 to 3 $\mathrm{dB}(\mathrm{A})$ for both $\mathrm{L}_{\text {den }}$ and $\mathrm{L}_{\text {night }}$ indicators (Fig. 2).

Of the total of 42 locations, $\mathrm{L}_{\mathrm{den}}$ has a negative 'before'-'after'(before: 2005-2009, after: 20102013) change on 24, while 17 locations present an increase in the indicators and one has no change. Also, $\mathrm{L}_{\text {night }}$ indicator is reduced in 25 locations and increased in 17 (Fig. 3).

4.2 Noise indicators and traffic volume

As shown in Fig. 2, the change of noise level follows the change in traffic volume with maximum values in 2008 and 2009 and minimum in 2013. Noise measurements increase during the years of high traffic and then, with some fluctuations, return to the levels before the increase of traffic. This trend appears in most of the locations.

In Fig. 4, the number of locations where $\mathrm{L}_{\text {den }}$ was measured over $70 \mathrm{~dB}(\mathrm{~A})$ and $\mathrm{L}_{\text {night }}$ over 60 $\mathrm{dB}(\mathrm{A})$ in years 2005, 2009 and 2013 is presented. The peak of overlimits' measurements appeared in 2009. The overlimits measurements were 31 for $\mathrm{L}_{\text {den }}$ and 38 for $\mathrm{L}_{\text {night }}$. By the shape of distribution curves, it is clear that in 2013 there is a 'return' to the 2005 curve. Also, 2013 has the smallest number overlimits measurements ( 8 for $\mathrm{L}_{\text {den }}$ and 12 for $\mathrm{L}_{\text {night }}$ ).

Figures 5 and 6 present the values of noise indicators in three different categories in which the locations of measurements are separated. Namely: (a) the indicator $\mathrm{L}_{\text {den }}$ is significantly higher in sections with high traffic volumes.

The average value is $71.3 \mathrm{~dB}(\mathrm{~A})$ for high traffic volume sections, $69.9 \mathrm{~dB}(\mathrm{~A})$ for middle volume sections and $68.2 \mathrm{~dB}(\mathrm{~A})$ for low volume sections. The difference between low and high volume 


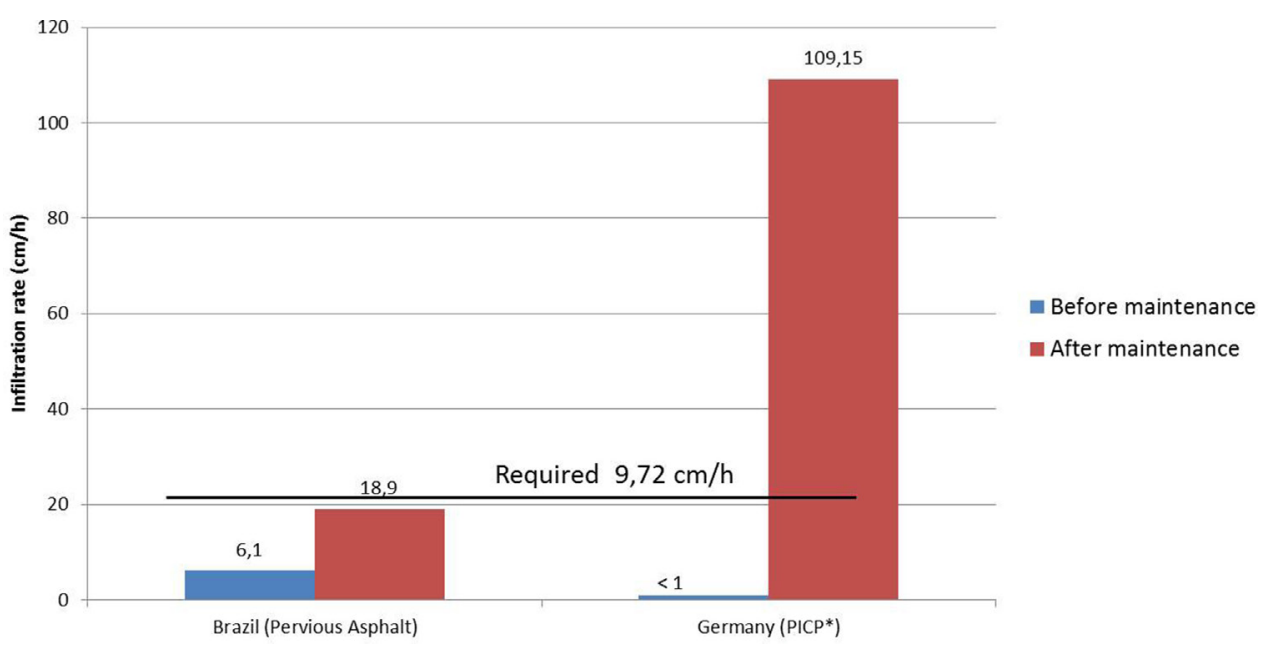

Figure 2: Traffic noise level and traffic volume evolution (hourly average), at 42 locations for the period 2005-2013.

locations is $3.1 \mathrm{~dB}(\mathrm{~A})$, as per Fig. 5 . $\mathrm{L}_{\text {night }}$ index has, average $63.5 \mathrm{~dB}(\mathrm{~A})$ for high volume sections, $62 \mathrm{~dB}(\mathrm{~A})$ for middle volume sections and $60.1 \mathrm{~dB}(\mathrm{~A})$ for those with low traffic. The difference between low and high values is $3.4 \mathrm{~dB}(\mathrm{~A})$ as per Fig. 6 .

At the same time, we cannot draw clear conclusions regarding the relationship of speed change and noise indicators. The 24-h average speed shows a minimum value in 2008 and then strongly growths during years of crisis, where it reaches the 9-year peak, in 2012 with $104.4 \mathrm{~km} / \mathrm{h}$. In 2013, speed is very close to the minimum value of the whole period, with $101 \mathrm{~km} / \mathrm{h}$. Respectively, the average 8-h speed shows fluctuations during the years, while there is a clear trend that begins in 2009, when it receives the maximum value $(108 \mathrm{~km} / \mathrm{h})$, and continues until 2013 , when it drops to the minimum value of $102.2 \mathrm{~km} / \mathrm{h}$ (Fig. 7).

Since speed is one of the most determining factors of traffic noise, it is important to further analyze these results to investigate if these variations are expected to affect noise levels over the years.

The average 24-h speed increase due to the fact that the high traffic volume sections show high growth of speed during peak hours after the year of 2010. Figure 8 shows the morning peak hours speed (8-10 am) in years with the highest traffic volume (2008 and 2009) compared with the years with lower one (2012 and 2013). At the areas of low traffic, there are not significant differences and speed is close to free-flow speed for a 3-lane motorway section that is over $100 \mathrm{~km} / \mathrm{h}$. In contrast, when traffic volume reaches higher values, speed in 2008 and 2009 decreases, in most of the cases below $80 \mathrm{~km} / \mathrm{h}$, while in 2012 and 2013 it remains in higher values and almost all measurements are over $90 \mathrm{~km} / \mathrm{h}$.

Regarding 8-h speed, since this refers to low traffic conditions (night), any change is due to the users' driving behavior. Thus, the decrease during the years of crisis from $108 \mathrm{~km} / \mathrm{h}$ in 2009 to $102.2 \mathrm{~km} / \mathrm{h}$ in $2013(-5.4 \%)$ is perfectly normal. This behavior causes lower consumptions and travel expenses as well (Fig. 7).

\subsection{Correlations of noise indicators, traffic flow and speed}

As a result from the previous analysis, the changes of speed do not coincide with the changes of noise (e.g. 24-h speed increase has not been followed by $\mathrm{L}_{\mathrm{den}}$ increase for the period 2007 to 2012). 


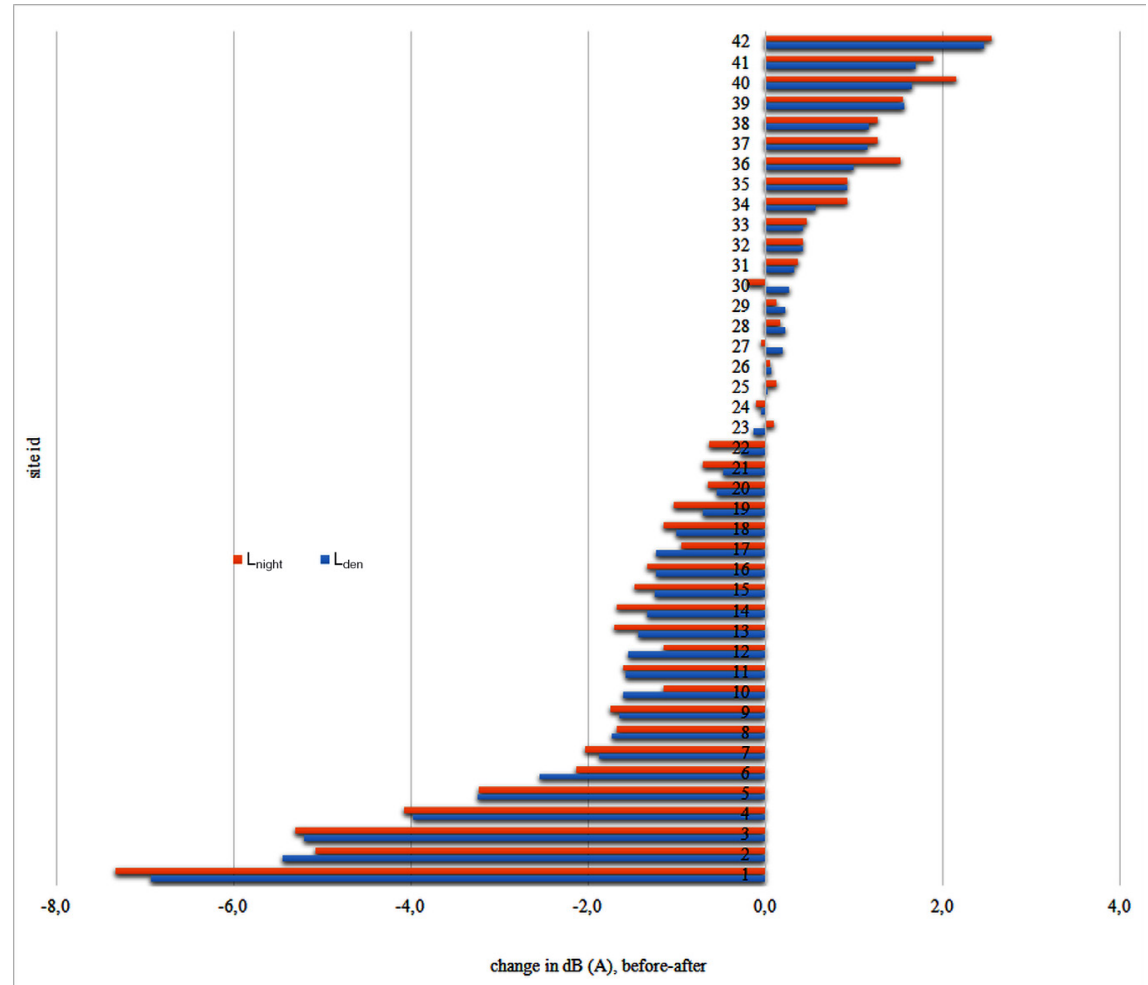

Figure 3: Before - after changes of environmental road traffic noise level in 42 locations at Athens ring road.
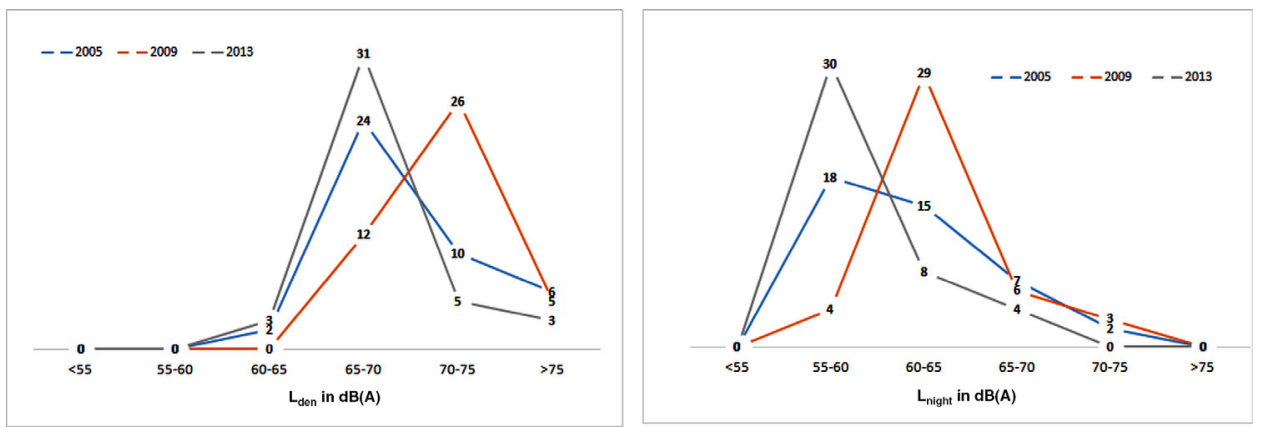

Figure 4: Distribution of $\mathrm{L}_{\text {den }} \& \mathrm{~L}_{\text {night }}$ noise indices (intervals) for: 2005-2009-2013.

Also, for the specific motorway system, speed contribution in noise level formation seems not that important. 


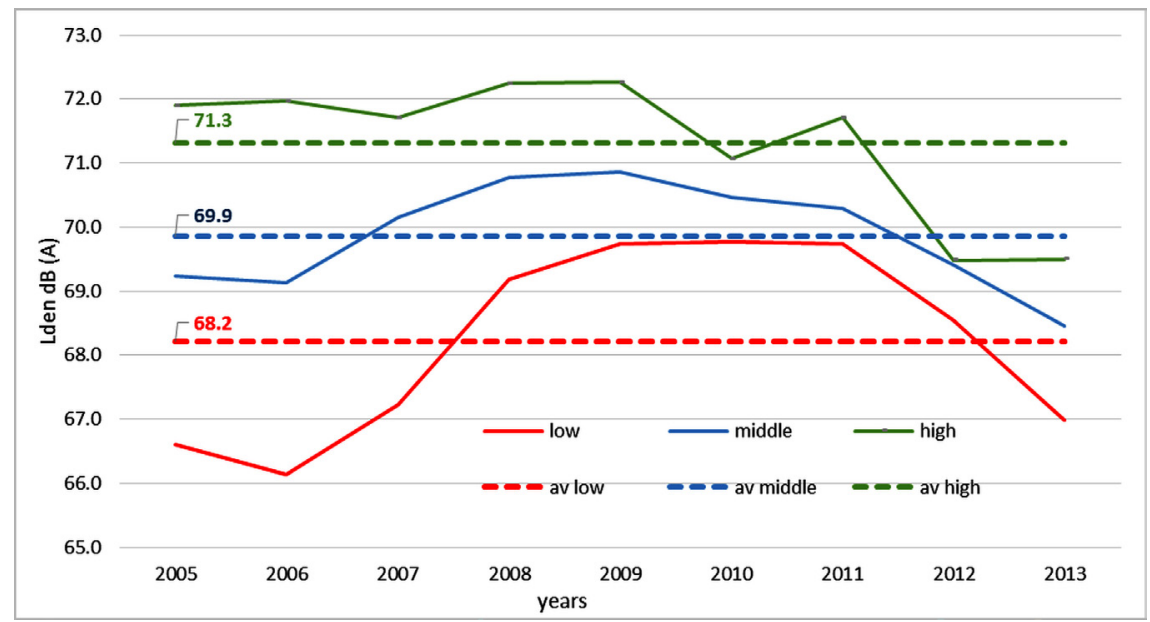

Figure 5: $\mathrm{L}_{\text {den }}$ fluctuation per traffic volume level (high, middle and low), 2005-2013.

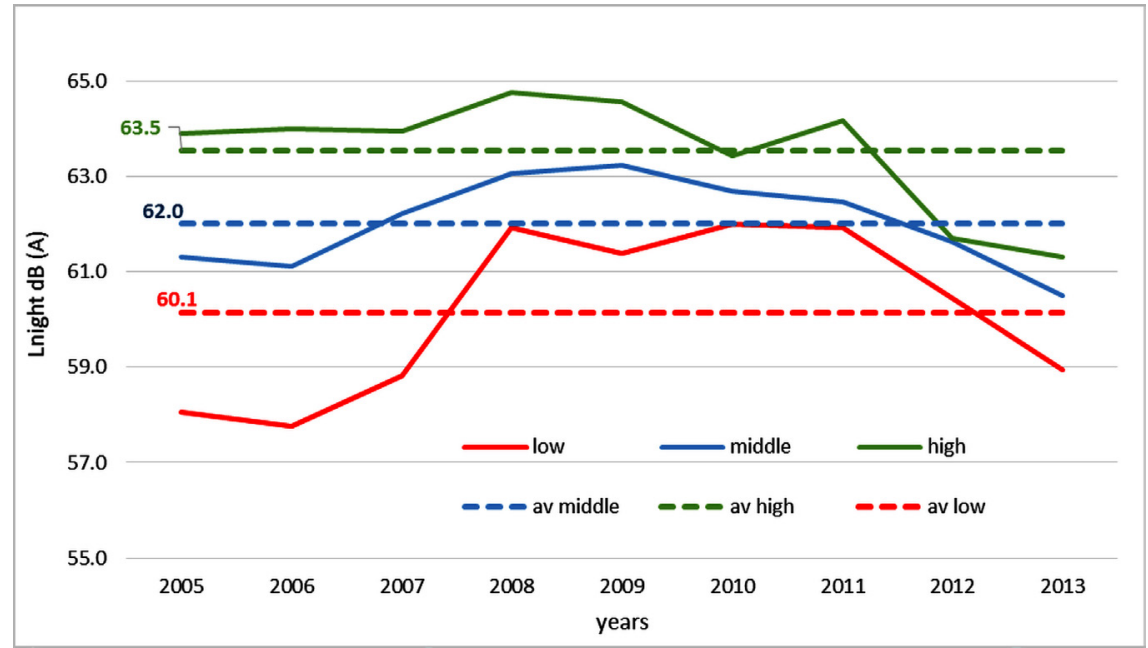

Figure 6: $\mathrm{L}_{\text {night }}$ per traffic volume level, (high, middle, low) 2005-2013.

On the contrary, it seems that there is a correlation of noise and traffic volume. To explore the relationship between noise level, traffic volume and speed, correlation tests are implemented. The results are shown in Table 2.

According to the results of the tests, there is a moderate positive relationship between $\mathrm{L}_{\mathrm{den}}$ and 24-h traffic volume $(\mathrm{r}=0.354, \mathrm{n}=378, \mathrm{p}=0.05)$. On the other hand, there is a non-significant correlation of $\mathrm{L}_{\mathrm{den}}$ and 24-h speed. Regarding $\mathrm{L}_{\text {night }}$, there is a moderate (and almost strong one) positive relationship between $\mathrm{L}_{\text {night }}$ and 8-h traffic volume $(\mathrm{r}=0.395, \mathrm{n}=378, \mathrm{p}=0.05)$. A negligible relationship between $L_{\text {den }}$ and 8-h speed $(r=0.186, n=378, p=0.05)$ is observed. 


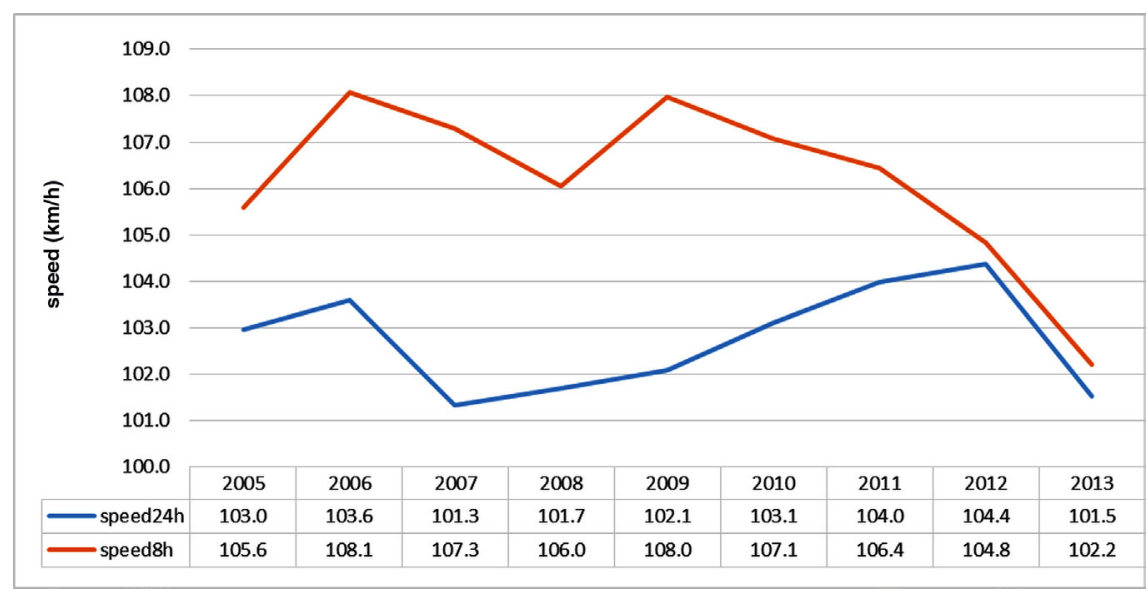

Figure 7: 24h speed and 8h speed evolution for the period 2005-2013.

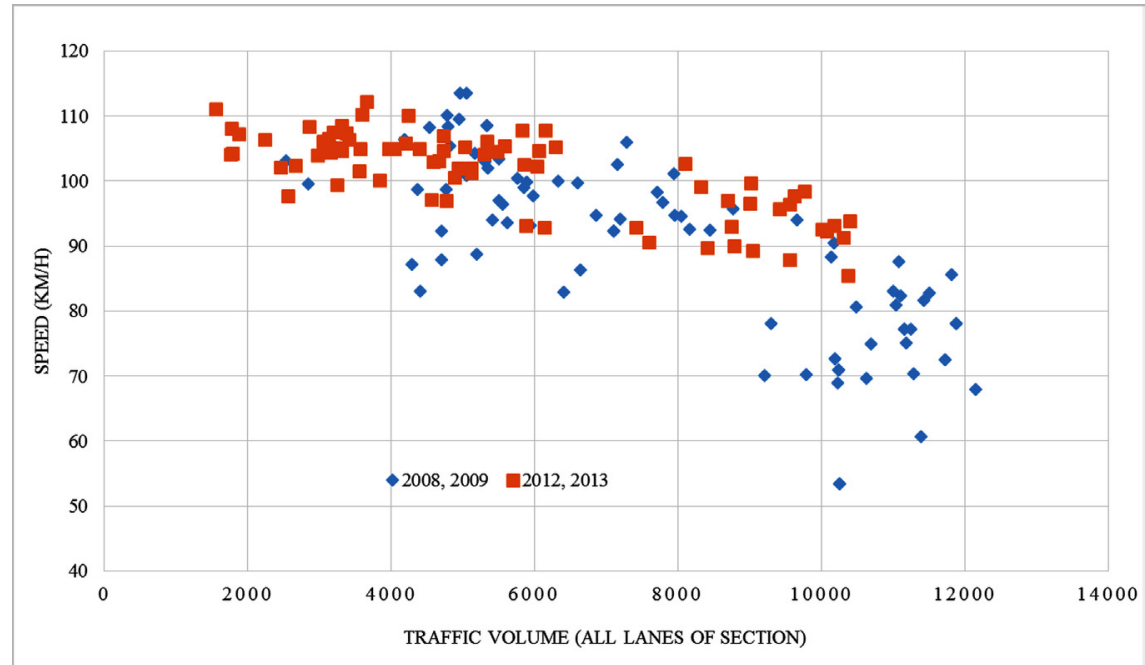

Figure 8: Speed-Flow diagram for morning peak hours (8:00-10:00 am), years of max and min traffic volumes.

We conclude, therefore, that indeed the indicator $\mathrm{L}_{\mathrm{den}}$ is dependent to a degree on traffic volume and not on the speed, while the same relationship exists for the $\mathrm{L}_{\text {night }}$ which, additionally, seems to have a more expected relationship with speed (speed increase in non-congested traffic conditions imply an increase of noise level).

\section{CONCLUSIONS}

In the present study, 42 locations of noise measurement in Athens Ring Road (Attica Tollway) are analyzed during a 9-year period. According to the macroeconomic data presented above, the great reces- 
Table 2: Correlations test of noise indicators, traffic flow and speed.

\begin{tabular}{llccc}
\hline & & volume24 & $\mathbf{L}_{\text {den }}$ & speed24 \\
\hline $\mathbf{L}_{\text {den }}$ & Pearson Correlation & $0.354^{*}$ & 1 & -0.083 \\
& Sig. (2-tailed) & 0.000 & & 0.107 \\
& $\mathrm{~N}$ & 378 & 378 & 378 \\
\hline & & volume8 & $\mathbf{L}_{\text {night }}$ & speed8 \\
\hline $\mathbf{L}_{\text {night }}$ & Pearson Correlation & $0.395^{*}$ & 1 & $0.186^{*}$ \\
& Sig. (2-tailed) & 0.000 & & 0.000 \\
& $\mathrm{~N}$ & 378 & 378 & 378 \\
\hline
\end{tabular}

* Correlation is significant at the 0.01 level (2-tailed).

sion period started in 2010 and is still continuing. Overall, it appears that during the years of current recession, total traffic noise level has been reduced as a result of the relevant road traffic volume reduction. More specifically, traffic volume reduction between 2009 (the year of highest values of traffic) and 2013 is $34.7 \%$ while the noise level was reduced for both $\mathrm{L}_{\text {den }}$ and $\mathrm{L}_{\text {night }}$ indicators circa $3 \mathrm{~dB}(\mathrm{~A})$.

Also, measurements show that regarding the maximum permissible limit values, the number of locations where $\mathrm{L}_{\text {den }}>70 \mathrm{~dB}(\mathrm{~A})$ and $\mathrm{L}_{\text {night }}>60 \mathrm{~dB}(\mathrm{~A})$ has significantly decreased during the last years of recession.

According to the data analyzed, $\mathrm{L}_{\text {den }}$ indicator is dependent on traffic volume and not on the speed, while the same relationship stands for the $\mathrm{L}_{\text {night }}$, as well. Speed seems to be more independent of noise level evolution and the reason is that despite the traffic volume decrease, average speed has moved to higher levels during daylight hours (less congested hours) and to lower levels during the night when drivers minimize the fuel consumption for economy reasons.

Although the end of the recession followed by the stabilization and the expected improvement of the Greece economy will probably lead to an adjustment of noise in higher levels. In addition, some side effects of the economic recession, such as the large increase of the average age of the vehicle fleet or the poor maintenance, may lead to worst environmental conditions.

\section{REFERENCES}

[1] Button, K., City management and urban environmental indicators. Ecological Economics, 40(2), pp. 217-233, 2002. doi: 10.1016/S0921-8009(01)00255-5.

[2] Lia, F., Liub, X., Hua, D., Wanga, R., Yanga, W., Lia, D. \& Zhaoa, D., Measurement indicators and an evaluation approach for assessing urban sustainable development: a case study for China's Jining City. Landscape and Urban Planning, 90(3-4), pp. 134-142, 2009. doi: 10.1016/j.landurbplan.2008.10.022.

[3] Shu, S., Yang, P. \& Zhu, Y., Correlation of noise levels and particulate matter concentrations near two major freeways in Los Angeles, California. Environmental Pollution, 193, 2014, pp. 130-137, 2014. doi: 10.1016/j.envpol.2014.06.025.

[4] Ninga, Z., Huddaa, N., Dahera, N., Kama, W., Hernerb, J., Kozawab, K., Marab, S. \& Sioutasa, C., Impact of roadside noise barriers on particle size distributions and pollutants concentrations near freeways. Atmospheric Environment, 44(26), pp. 3118-3127, 2010. doi: 10.1016/j. atmosenv.2010.05.033. 
[5] Fiedler, P.E.K. \& Zannin, P.H.T., Evaluation of noise pollution in urban traffic hubs - noise maps and measurements. Environmental Impact Assessment Review, 51, pp. 1-9, 2015. doi: 10.1016/j.eiar.2014.09.014.

[6] Leea, E.Y., Jerretta, M., Rossb, Z., Cooganc, P.F. \& Setoa, E.Y.W., Assessment of trafficrelated noise in three cities in the United States. Environmental Research, 132, pp. 182-189, 2014. doi: 10.1016/j.envres.2014.03.005.

[7] Gallo, M., De Luca, G. \& De Martinis, V., The effects of urban traffic plans on noise abatement: a case study. WIT Transactions on Ecology and the Environment, The Sustainable City IX 191(2), pp. 583-595, 2014. doi: 10.2495/SC140491.

[8] Romeu, J., Genescà, M., Pàmies, T. \& Jiménez, S., Street categorization for the estimation of day levels using short-term measurements. Applied Acoustics, 72(4), pp. 569-577, 2011. doi: 10.1016/j.apacoust.2010.09.012.

[9] Makarewicz, R. \& Gałuszka, M., Road traffic noise prediction based on speed-flow diagram. Applied Acoustics, 72, pp. 190-195, 2011. doi: 10.1016/j.apacoust.2010.11.010.

[10] Vogiatzis, K., Environmental noise and air pollution monitoring in Athens Ring Road ('Attiki Odos') - an important parameter for sustainable urban development. International Journal of Sustainable Development and Planning, 2015. ISSN: 1743-7601 (paper format), ISSN: 1743761X (online), 10(4), pp. 528-543, 2015. http://www.witpress.com/journals. doi: 10.2495/ SDP-V1-N0-4-16.

[11] Vogiatzis, K. (TT\&E S.A.), Environmental noise study of Attiki Odos: strategic noise maps \& noise action plans, 2010.

[12] Kopelias, P., Vogiatzis, K.E. \& Skbardonis, A., The impact of congestion management on air pollution emissions in urban freeways. International Journal of Sustainable Development \& Planning, 8(3), pp. 400-412, 2013. doi: http://dx.doi.org/10.2495/sdp-v8-n3-400-412

[13] Directive 2002/49/EC of the European Parliament and of the Council of 25 June 2002, Relating to the assessment and management of environmental noise. Official Journal of the European Communities L 189/12 18.7.2002.

[14] WHO-JRC, Burden of disease from environmental noise - quantification of healthy life years lost in Europe European Centre for Environment and Health \& JRC EU, 2011.

[15] MD 211773/2012 (ФEK 1367/B/27-4-2012), Criteria \& noise max levels for the indices according to the Directive 2002/49/EC of the European parliament and of the council of 25 June 2002 relating to the assessment and management of environmental noise, 2002.

[16] Vogiatzis, K. \& Psychas, K., Legal aspects on environmental noise and urban soundscape rehabilitation in Mediterranean countries: the case of Greece. International Journal of Sustainable Development and Planning, 7(4), pp. 484-494, 2012. 2013, ISSN: 1743-7601 (paper format), ISSN: 1743-761X (online), http://journals.witpress.com. doi: 10.2495/ SDP-V8-N2-173-185.

[17] Vogiatzis, K., Environmental noise and vibration monitoring and assessment of major road transportation networks: the case of Elefsina (Athens) - Korinthos Motorway (2008-2011). International Journal of Sustainable Development and Planning Volume, 8(2), pp. 173-185, 2013. ISSN: 1743-7601 (paper format), ISSN: 1743-761X (online), http://journals.witpress. com. doi: 10.2495/SDP-V8-N2-173-185.

[18] ISO 1996-2: 1987, Acoustics - description and measurement of environmental noise - Part 2: acquisition of data pertinent to land use (revised by the ISO 1996-2:2007 Acousticsdescription, measurement and assessment of environmental noise - Part 2: determination of environmental noise levels). 
[19] Hellenic Statistical Authority (ELSTAT), reports available at http://www.statistics.gr.

[20] Serbis, D., Chaziris, A. \& Vorvolakos, U. Traffic volume changes in main highway of Athens, Greece. Conference of Transportation and Economic Crisis, Hellenic Institute of Transportation Engineers, Athens, Greece, 2013.

[21] Annual Reports of Attica Tollway Operations Company, available at http://www.aodos.gr/. 